\title{
Robust neutralizing antibodies to SARS-CoV-2 infection persist for months
}

\author{
Ania Wajnberg'*, Fatima Amanat ${ }^{2,3}$, Adolfo Firpo ${ }^{4}$, Deena R. Altman ${ }^{5}$, Mark J. Bailey', Mayce Mansour', \\ Meagan McMahon ${ }^{2}$, Philip Meade ${ }^{2,3}$, Damodara Rao Mendu ${ }^{4}$, Kimberly Muellers ${ }^{1}$, Daniel Stadlbauer ${ }^{2}$, \\ Kimberly Stone ${ }^{1}$, Shirin Strohmeier ${ }^{2}$, Viviana Simon ${ }^{2}$, Judith Aberg ${ }^{5}$, David L. Reich ${ }^{6}$, Florian Krammer ${ }^{2 *}$, \\ Carlos Cordon-Cardo ${ }^{4 *}$
}

${ }^{1}$ Department of General Internal Medicine, Icahn School of Medicine at Mount Sinai, New York, NY 10029, USA. ${ }^{2}$ Department of Microbiology, Icahn School of Medicine at Mount Sinai, New York, NY 10029, USA. ${ }^{3}$ Graduate School of Biomedical Sciences, Icahn School of Medicine at Mount Sinai, New York, NY 10029, USA. ${ }^{4}$ Clinical Microbiology Laboratory, Department of Pathology, Icahn School of Medicine at Mount Sinai, New York, NY 10029, USA. ${ }^{5}$ Division of Infectious Diseases, Department of Medicine, Icahn School of Medicine at Mount Sinai, New York, NY 10029, USA. ${ }^{6}$ Department of Anesthesiology, Perioperative and Pain Medicine, Icahn School of Medicine at Mount Sinai, New York, NY 10029, USA.

*Corresponding author. Email: ania.wajnberg@mountsinai.org (A.W.); florian.krammer@mssm.edu (F.K.); carlos.cordon-cardo@mssm.edu (C.C.-C.)

SARS-CoV-2 has caused a global pandemic with millions infected and numerous fatalities. Questions regarding the robustness, functionality, and longevity of the antibody response to the virus remain unanswered. Here we report that the vast majority of infected individuals with mild-to-moderate COVID-19 experience robust IgG antibody responses against the viral spike protein, based on a dataset of 30,082 individuals screened at Mount Sinai Health System in New York City. We also show that titers are relatively stable for at least a period approximating 5 months and that anti-spike binding titers significantly correlate with neutralization of authentic SARS-CoV-2. Our data suggests that more than $90 \%$ of seroconverters make detectible neutralizing antibody responses. These titers remain relatively stable for several months after infection.

Severe acute respiratory syndrome coronavirus 2 (SARS-CoV2) has infected millions of individuals globally and, as of October 2020, has led to the death of more than 1 million individuals. Although the antibody responses to severe coronavirus disease 2019 (COVID-19) have been relatively well characterized $(1,2)$, assessing the response in mild and asymptomatic cases is of high importance since they constitute the majority of infections. It will be critical to understand the robustness of the antibody response in these mild cases, including its longevity and its functionality, so as to inform serosurveys, as well as to determine levels and duration of antibody titers that may be protective from reinfection (3).

Antibodies to SARS-CoV-2 can target many of its encoded proteins, including structural and non-structural antigens. Thus far, two structural proteins have been utilized as target antigens for serological assays. One is the abundant nucleoprotein (NP), which is found inside the virus or inside infected cells. However, due to the biological function of NP and the fact that it is shielded from antibodies by viral or cellular membranes, it is unlikely that NP antibodies can directly neutralize SARS-CoV-2. The second structural protein often used as target for characterizing the immune response to SARS-CoV-2 is the spike protein. The spike is a large trimeric glycoprotein that contains the receptor binding domain (RBD), which the virus uses to dock to its cellular receptor angiotensin-converting enzyme 2 (ACE2) and for fusion of viral and cellular membranes $(4,5)$. It is known from other coronaviruses as well as for SARS-CoV-2 that the spike is the main, and potentially only target for neutralizing antibodies (6). Therefore, the assay used in this study to characterize the antibody response to SARS-CoV-2 is based on the trimerized, stabilized ectodomain of the spike protein (7). An enzyme-linked immunosorbent assay (ELISA) initially developed in early 2020 has been extensively used in research (710). The so-called Mount Sinai ELISA has high sensitivity (92.5\%) and specificity (100\%) as determined with an initial validation panel of samples (table S1). Furthermore, it has a positive predictive value (PPV) of $100 \%$, with a negative predictive value (NPV) of $99.6 \%$.

In March 2020, Mount Sinai Health System began to screen individuals for antibodies to SARS-CoV-2 to recruit volunteers as donors for convalescent plasma therapy (11). Screened patients either had confirmed SARS-CoV-2 infections by PCR, or suspected disease, defined as being told by a physician that symptoms may be related to SARS-CoV-2 or exposure to someone with confirmed SARS-CoV-2 infection. The vast majority of symptomatic cases that were screened experienced mild-to-moderate disease, with less than $5 \%$ requiring emergency department evaluation or hospitalization. Mount Sinai also offered the antibody test to all employees within our health system on a voluntary basis. By 6 October 
2020, Mount Sinai had screened 72,401 individuals with a total of 30,082 individuals testing positive (defined as detectible antibodies to the spike protein at a titer of 1:80 or higher) and 42,319 testing negative. The clinical laboratory ELISA set up results in discrete titers of either 1:80, 1:160, 1:320, 1:960, or $\geq 1: 2880$. Titers of 1:80 and 1:160 were categorized as low titers, $1: 320$ as moderate, and 1:960 and $\geq 1: 2880$ as high titers. For plasma therapy, titers of 1:320 or higher were initially deemed eligible. Of the 30,082 positive samples, 690 (2.29\%) had a titer of $1: 80,1453(4.83 \%)$ of $1: 160,6765$ (22.49\%) of 1:320, 9564 (31.79\%) of 1:960, and 11610 (38.60\%) of 1:2880 (Fig. 1). Thus, the vast majority of positive individuals have moderate-to-high titers of anti-spike antibodies. Of course, the argument could be made that we could be missing a number of individuals who had been infected with SARSCoV-2 and did not produce antibodies, since many individuals included in our dataset had never been tested by a nucleic acid amplification test (NAAT) for the virus. An earlier analysis performed with a smaller subset of 568 PCR-confirmed individuals using the same ELISA showed that $>99 \%$ of them developed an anti-spike antibody response (8). In a later dataset of 2347 patients who self-reported positive PCR, 95\% had positive antibody titers, indicating that we did not miss large numbers of patients and confirming our prior sensitivity findings. Thus, the rate of individuals who do not seroconvert after SARS-CoV-2 infection is low, although such individuals may exist, and the majority of responders mount titers of 1:320 or higher.

Determining the neutralizing effects of SARS-CoV-2 spike antibodies is critical to understanding possible protective effects of the immune response. Therefore, we performed a well-established, quantitative microneutralization assay (12) based on authentic SARS-CoV-2 with 120 samples of known ELISA titers ranging from "negative" to $\geq 1: 2880$. Neutralization titers significantly correlated (Spearman $\rho=0.87$, $P<0.0001$ ) with spike-binding titers (Fig. 2A). Although there was some variability, sera with 1:320, 1:960, and $\geq 1: 2880$ ELISA titers had geometric mean $50 \%$ inhibitory dilutions $\left(\mathrm{ID}_{50}\right)$ of approximately 1:30, 1:75, and 1:550, respectively. Considering any neutralizing activity above background, approximately $50 \%$ of sera in the 1:80 to 1:160 titer range had neutralizing activity, $90 \%$ in the 1:320 range had neutralizing activity, and all sera in the 1:960 to $\geq 1: 2880$ range had neutralizing activity (Fig. 2B). Only one of the negative samples showed activity slightly above background, which was potentially an ELISA false negative.

Another important question is longevity of the antibody response to the spike. To assess the medium-range stability of serum antibody titers against the spike protein, we recalled 121 plasma donors at a variety of titer levels who had initially been screened at approximately day 30 post symptom onset for two additional time points. The mean interval between the initial titer measurement and the second was 52 days (range 33 to 67 days). This set the second time point at a mean of 82 days post symptom onset (range 52 to 104 days) and the third time point at 148 days post symptom onset (range 113 to 186 days). When we compared overall titers, we observed a slight drop from a geometric mean titer (GMT) of 764 to a GMT of 690 from the first to the second time point and another drop to a GMT of 404 for the last time point (Fig. 3A). In the higher titer range of 1:2880 and 1:960, we also observed a slow decline in titer over time (Fig. 3, B and C). Surprisingly, but in agreement with earlier observations from our group that seroconversion in mild COVID-19 cases might take longer time to mount (8), we saw an initial increase in individuals who had an initial titer of 1:320, 1:160, or $1: 80$ (Fig. 3, D to F). Titers in these groups declined to approximately day 30 levels on day 148 . Notably, one individual in the initial 1:80 group dropped from a 1:80 titer to being negative at the day 82 time point and two more lost reactivity at the day 148 time point, indicating that very low initial titers might drop to undetectable levels over time. Neutralizing antibody titers followed titers measured by ELISA (Fig. 3G) and a good correlation between neutralization and ELISA titers was still observed on day 148 (Fig. 3H). The initial serum antibody titer was likely produced by plasmablasts, and plasmablast-derived antibody peaks 2 to 3 weeks post symptom onset. Given an IgG half-life of approximately 21 days, the sustained antibody titers observed here over time are likely produced by long-lived plasma cells in the bone marrow. Of note, our observations were in contrast to a recent report that found waning titers 8 weeks post virus infection as compared to acute responses (13). Especially in asymptomatic cases, antibody responses disappeared after 8 weeks in $40 \%$ of individuals in that study. However, the antibodies measured in that paper targeted the NP plus a single linear spike epitope. The same paper also reported relatively stable (slightly declining) neutralizing antibody titers, which shows much higher concordance with our present findings. Thus, the stability of the antibody response over time may also depend on the target antigen.

For many different viral infections, correlates of protection have been established. These correlates are usually based on a specific level of antibody acquired through vaccination or natural infection that significantly reduces the risk of (re)infection. Examples are the hemagglutination inhibition titer for influenza virus, where a 1:40 titer reduces the risk of getting infected by $50 \%$ (14). Similar titers have been established for measles virus (an $\mathrm{ID}_{50}$ titer of 1:120), hepatitis A virus, hepatitis B virus, and many others (15). These titers have facilitated vaccine development significantly. For some viruses and vaccines, the kinetics of the antibody response is also known, allowing for an accurate prediction of how long protection will last (16). 
It is still unclear if infection with SARS-CoV-2 in humans protects from reinfection and for how long. We know from work with common human coronaviruses that neutralizing antibodies are induced and these antibodies can last for years and provide protection from reinfection or attenuate disease, even if individuals get reinfected (17). Furthermore, we now know from non-human primate models that infection with SARS-CoV-2 does protect from reinfection for at least some time $(18,19)$. We also know that transferring serum of convalescent animals or neutralizing monoclonal antibodies to naïve animals can be protective and reduces virus replication significantly $(20,21)$. Finally, vaccine-induced neutralizing antibody titers have been established as a correlate of protection in non-human primates (22). Notably, these titers were relatively low and in the lower range of the titers observed here. Our data reveal that individuals who have recovered from mild COVID-19 experience relatively robust antibody responses to the spike which correlate significantly with neutralization of authentic SARS-CoV-2 virus. Furthermore, the vast majority of individuals with antibody titers of 1:320 or higher show neutralizing activity in their serum. Consistent with data for the human coronaviruses, SARS-CoV-1 and Middle Eastern respiratory syndrome (MERS)-CoV (17), we also find stable antibody titers over a period of at least 3 months and only modest declines at the 5-month time point. We plan to follow this cohort over longer intervals of time. Although this cannot provide conclusive evidence that these antibody responses protect from reinfection, we believe it is very likely that they will decrease the odds ratio of reinfection, and may attenuate disease in the case of breakthrough infection. We believe it is imperative to swiftly perform studies to investigate and establish a correlate of protection from infection with SARS-CoV-2. A correlate of protection, combined with a better understanding of antibody kinetics to the spike protein, would inform policy regarding the COVID-19 pandemic and would be beneficial to vaccine development efforts.

\section{REFERENCES AND NOTES}

1. L. Liu, K. K.-W. To, K.-H. Chan, Y.-C. Wong, R. Zhou, K.-Y. Kwan, C. H.-Y. Fong, L.-L. Chen, C. Y.-K. Choi, L. Lu, O. T.-Y. Tsang, W.-S. Leung, W.-K. To, I. F.-N. Hung, K.Y. Yuen, Z. Chen, High neutralizing antibody titer in intensive care unit patients with COVID-19. Emerg. Microbes Infect. 9, 1664-1670 (2020). doi:10.1080/22221751.2020.1791738 Medline

2. Q. X. Long, B.-Z. Liu, H.-J. Deng, G.-C. Wu, K. Deng, Y.-K. Chen, P. Liao, J.-F. Qiu, Y. Lin, X.-F. Cai, D.-Q. Wang, Y. Hu, J.-H. Ren, N. Tang, Y.-Y. Xu, L.-H. Yu, Z. Mo, F. Gong, X.-L. Zhang, W.-G. Tian, L. Hu, X.-X. Zhang, J.-L. Xiang, H.-X. Du, H.-W. Liu, C.-H. Lang, X.-H. Luo, S.-B. Wu, X.-P. Cui, Z. Zhou, M.-M. Zhu, J. Wang, C.-J. Xue, X.-F. Li, L. Wang, Z.-J. Li, K. Wang, C.-C. Niu, Q.-J. Yang, X.-J. Tang, Y. Zhang, X.M. Liu, J.-J. Li, D.-C. Zhang, F. Zhang, P. Liu, J. Yuan, Q. Li, J.-L. Hu, J. Chen, A.-L. Huang, Antibody responses to SARS-CoV-2 in patients with COVID-19. Nat. Med. 26, 845-848 (2020). doi:10.1038/s41591-020-0897-1 Medline

3. F. Krammer, V. Simon, Serology assays to manage COVID-19. Science 368, 1060 1061 (2020). doi:10.1126/science.abc1227 Medline

4. D. Wrapp, N. Wang, K. S. Corbett, J. A. Goldsmith, C.-L. Hsieh, O. Abiona, B. S. Graham, J. S. McLellan, Cryo-EM structure of the 2019-nCoV spike in the $\begin{array}{llll}\text { prefusion conformation. Science 367, 1260-1263 (2020). } & \text {. }\end{array}$ doi:10.1126/science.abb2507 Medline
5. M. Letko, A. Marzi, V. Munster, Functional assessment of cell entry and receptor usage for SARS-CoV-2 and other lineage B betacoronaviruses. Nat. Microbiol. 5 , 562-569 (2020). doi:10.1038/s41564-020-0688-y Medline

6. F. Amanat, F. Krammer, SARS-CoV-2 vaccines: Status report. Immunity 52, 583589 (2020). doi:10.1016/i.immuni.2020.03.007 Medline

7. F. Amanat, D. Stadlbauer, S. Strohmeier, T. H. O. Nguyen, V. Chromikova, M. McMahon, K. Jiang, G. A. Arunkumar, D. Jurczyszak, J. Polanco, M. BermudezGonzalez, G. Kleiner, T. Aydillo, L. Miorin, D. S. Fierer, L. A. Lugo, E. M. Kojic, J. Stoever, S. T. H. Liu, C. Cunningham-Rundles, P. L. Felgner, T. Moran, A. GarcíaSastre, D. Caplivski, A. C. Cheng, K. Kedzierska, O. Vapalahti, J. M. Hepojoki, V. Simon, F. Krammer, A serological assay to detect SARS-CoV-2 seroconversion in humans. Nat. Med. 26, 1033-1036 (2020). doi:10.1038/s41591-020-0913-5 Medline

8. A. Wajnberg, M. Mansour, E. Leven, N. M. Bouvier, G. Patel, A. Firpo-Betancourt, R. Mendu, J. Jhang, S. Arinsburg, M. Gitman, J. Houldsworth, E. Sordillo, A. PanizMondolfi, I. Baine, V. Simon, J. Aberg, F. Krammer, D. Reich, C. Cordon-Cardo, Humoral response and PCR positivity in patients with COVID-19 in the New York City region, USA: An observational study. Lancet 10.1016/S26665247(20)30120-8 (2020). doi:10.1016/S2666-5247(20)30120-8 Medline

9. D. Stadlbauer, J. Tan, K. Jiang, M. Hernandez, S. Fabre, F. Amanat, C. Teo, G. A. Arunkumar, M. McMahon, J. Jhang, M. Nowak, V. Simon, E. Sordillo, H. van Bakel, F. Krammer, Seroconversion of a city: Longitudinal monitoring of SARS-CoV-2 seroprevalence in New York City. medRxiv 2020.06.2028.20142190 [Preprint]. 29 June 2020. https://doi.org/10.1101/2020.06.28.20142190.

10. D. Stadlbauer, F. Amanat, V. Chromikova, K. Jiang, S. Strohmeier, G. A. Arunkumar, J. Tan, D. Bhavsar, C. Capuano, E. Kirkpatrick, P. Meade, R. N. Brito, C. Teo, M. McMahon, V. Simon, F. Krammer, SARS-CoV-2 seroconversion in humans: A detailed protocol for a serological assay, antigen production, and test setup. Curr. Protoc. Microbiol. 57, e100 (2020). doi:10.1002/cpmc.100 Medline

11. S. T. H. Liu, H.-M. Lin, I. Baine, A. Wajnberg, J. P. Gumprecht, F. Rahman, D. Rodriguez, P. Tandon, A. Bassily-Marcus, J. Bander, C. Sanky, A. Dupper, A. Zheng, F. T. Nguyen, F. Amanat, D. Stadlbauer, D. R. Altman, B. K. Chen, F. Krammer, D. R. Mendu, A. Firpo-Betancourt, M. A. Levin, E. Bagiella, A. Casadevall, C. Cordon-Cardo, J. S. Jhang, S. A. Arinsburg, D. L. Reich, J. A. Aberg, N. M. Bouvier, Convalescent plasma treatment of severe COVID-19: A propensity scorematched control study. Nat. Med. 10.1038/s41591-020-1088-9 (2020). doi:10.1038/s41591-020-1088-9 Medline

12. F. Amanat, K. M. White, L. Miorin, S. Strohmeier, M. McMahon, P. Meade, W.-C. Liu, R. A. Albrecht, V. Simon, L. Martinez-Sobrido, T. Moran, A. García-Sastre, F. Krammer, An in vitro microneutralization assay for SARS-CoV-2 serology and drug screening. Curr. Protoc. Microbiol. 58, e108 (2020). doi:10.1002/cpmc.108 Medline

13. Q. X. Long, X.-J. Tang, Q.-L. Shi, Q. Li, H.-J. Deng, J. Yuan, J.-L. Hu, W. Xu, Y. Zhang, F.-J. Lv, K. Su, F. Zhang, J. Gong, B. Wu, X.-M. Liu, J.-J. Li, J.-F. Qiu, J. Chen, A.-L. Huang, Clinical and immunological assessment of asymptomatic SARS-CoV-2 infections. Nat. Med. 26, 1200-1204 (2020). doi:10.1038/s41591-020-0965-6 Medline

14. F. Krammer, J. P. Weir, O. Engelhardt, J. M. Katz, R. J. Cox, Meeting report and review: Immunological assays and correlates of protection for next-generation influenza vaccines. Influenza Other Respir. Viruses 14, 237-243 (2020). doi:10.1111/irv.12706 Medline

15. S. A. Plotkin, Correlates of protection induced by vaccination. Clin. Vaccine Immunol. 17, 1055-1065 (2010). doi:10.1128/CVI.00131-10 Medline

16. K. Van Herck, P. Van Damme, Inactivated hepatitis A vaccine-induced antibodies: Follow-up and estimates of long-term persistence. J. Med. Virol. 63, 1-7 (2001). doi:10.1002/1096-9071(200101)63:1<1:AID-JMV1000>3.0.C0:2-U Medline

17. A. T. Huang, B. Garcia-Carreras, M. D. T. Hitchings, B. Yang, L. C. Katzelnick, S. M. Rattigan, B. A. Borgert, C. A. Moreno, B. D. Solomon, L. Trimmer-Smith, V. Etienne, I. Rodriguez-Barraquer, J. Lessler, H. Salje, D. S. Burke, A. Wesolowski, D. A. T. Cummings, A systematic review of antibody mediated immunity to coronaviruses: Kinetics, correlates of protection, and association with severity Nat. Commun. 11, 4704 (2020). doi:10.1038/s41467-020-18450-4 Medline

18. W. Deng, L. Bao, J. Liu, C. Xiao, J. Liu, J. Xue, Q. Lv, F. Qi, H. Gao, P. Yu, Y. Xu, Y. Qu, F. Li, Z. Xiang, H. Yu, S. Gong, M. Liu, G. Wang, S. Wang, Z. Song, Y. Liu, W. Zhao, Y. Han, L. Zhao, X. Liu, Q. Wei, C. Qin, Primary exposure to SARS-CoV-2 protects 
against reinfection in rhesus macaques. Science 369, 818-823 (2020). doi:10.1126/science.abc5343 Medline

19. A. Chandrashekar, J. Liu, A. J. Martinot, K. McMahan, N. B. Mercado, L. Peter, L. H. Tostanoski, J. Yu, Z. Maliga, M. Nekorchuk, K. Busman-Sahay, M. Terry, L. M. Wrijil, S. Ducat, D. R. Martinez, C. Atyeo, S. Fischinger, J. S. Burke, M. D. Slein, L. Pessaint, A. Van Ry, J. Greenhouse, T. Taylor, K. Blade, A. Cook, B. Finneyfrock, R. Brown, E. Teow, J. Velasco, R. Zahn, F. Wegmann, P. Abbink, E. A. Bondzie, G. Dagotto, M. S. Gebre, X. He, C. Jacob-Dolan, N. Kordana, Z. Li, M. A. Lifton, S. H. Mahrokhian, L. F. Maxfield, R. Nityanandam, J. P. Nkolola, A. G. Schmidt, A. D. Miller, R. S. Baric, G. Alter, P. K. Sorger, J. D. Estes, H. Andersen, M. G. Lewis, D. H. Barouch, SARS-CoV-2 infection protects against rechallenge in rhesus macaques. Science 369, 812-817 (2020). doi:10.1126/science.abc4776 Medline

20. R. Shi, C. Shan, X. Duan, Z. Chen, P. Liu, J. Song, T. Song, X. Bi, C. Han, L. Wu, G. Gao, X. Hu, Y. Zhang, Z. Tong, W. Huang, W. J. Liu, G. Wu, B. Zhang, L. Wang, J. Qi, H. Feng, F.-S. Wang, Q. Wang, G. F. Gao, Z. Yuan, J. Yan, A human neutralizing antibody targets the receptor-binding site of SARS-CoV-2. Nature 584, 120-124 (2020). doi:10.1038/s41586-020-2381-y Medline

21. M. Imai, K. Iwatsuki-Horimoto, M. Hatta, S. Loeber, P. J. Halfmann, N. Nakajima, T. Watanabe, M. Ujie, K. Takahashi, M. Ito, S. Yamada, S. Fan, S. Chiba, M. Kuroda, L. Guan, K. Takada, T. Armbrust, A. Balogh, Y. Furusawa, M. Okuda, H. Ueki, A. Yasuhara, Y. Sakai-Tagawa, T. J. S. Lopes, M. Kiso, S. Yamayoshi, N. Kinoshita, N. Ohmagari, S. I. Hattori, M. Takeda, H. Mitsuya, F. Krammer, T. Suzuki, Y. Kawaoka, Syrian hamsters as a small animal model for SARS-CoV-2 infection and countermeasure development. Proc. Natl. Acad. Sci. U.S.A. 117, 16587-16595 (2020). doi:10.1073/pnas.2009799117 Medline

22. J. Yu, L. H. Tostanoski, L. Peter, N. B. Mercado, K. McMahan, S. H. Mahrokhian, J. P. Nkolola, J. Liu, Z. Li, A. Chandrashekar, D. R. Martinez, C. Loos, C. Atyeo, S. Fischinger, J. S. Burke, M. D. Slein, Y. Chen, A. Zuiani, F. J. N. Lelis, M. Travers, S. Habibi, L. Pessaint, A. Van Ry, K. Blade, R. Brown, A. Cook, B. Finneyfrock, A. Dodson, E. Teow, J. Velasco, R. Zahn, F. Wegmann, E. A. Bondzie, G. Dagotto, M. S. Gebre, X. He, C. Jacob-Dolan, M. Kirilova, N. Kordana, Z. Lin, L. F. Maxfield, F. Nampanya, R. Nityanandam, J. D. Ventura, H. Wan, Y. Cai, B. Chen, A. G. Schmidt, D. R. Wesemann, R. S. Baric, G. Alter, H. Andersen, M. G. Lewis, D. H. Barouch, DNA vaccine protection against SARS-CoV-2 in rhesus macaques. Science 369 , 806-811 (2020). doi:10.1126/science.abc6284 Medline

\section{ACKNOWLEDGMENTS}

We are grateful for the continuous expert guidance provided by the ISMMS Program for the Protection of Human Subjects (PPHS). We also thank R. A. Albrecht for oversight of the conventional BSL3 biocontainment facility, the medical students involved in the plasma convalescence program and D. Adhimoolam for invaluable help with data curation. Furthermore, we would like to express our gratitude to E. Lium and team at Mount Sinai Innovation Partners for continuous support and to V. Sarić and her team at Mount Sinai's Development Office for fundraising and for taking many little things off our shoulders during this difficult time. Finally, we would like to thank D. Charney and the Dean's Office for strong institutional support of our work. Funding: This work was partially supported by the NIAID Centers of Excellence for Influenza Research and Surveillance (CEIRS) contract HHSN272201400008C (FK), Collaborative Influenza Vaccine Innovation Centers (CIVIC) contract 75N93019C00051 (FK), and the generous support of the JPB foundation, the Open Philanthropy Project (\#2020-215611) and other philanthropic donations. Author contributions: A.W., D.R.A., M.J.B., M.Ma., K.M., K.S. and J.A. performed clinical activities. A.W., J.A., D.L.R., F.K. and C.C.-C. designed the study. A.W. and F.K. analyzed the data. A.F., M.Mc., P.M., D.R.M., D.S. and S.S. performed experiments. A.W., C.C.-C. and F.K. wrote the manuscript. All authors edited and approved the manuscript. Competing interests: Mount Sinai has licensed serological assays to commercial entities and has filed for patent protection for serological assays. J.A. reports grants for multicenter clinical trials: Atea (COVID), Frontier Technology (HIV), Gilead Sciences (COVID and HIV), Janssen (COVID and HIV), Merck (HIV), Pfizer (COVID), Regeneron (COVID) and Viiv (HIV). J.A. has received personal fees for Scientific Advisory Boards on HIV from Gilead, Janssen, Merck, Theratechnology and Viiv. Data and materials availability: All data are available in the manuscript or the supplementary materials. This work is licensed under a Creative
Commons Attribution 4.0 International (CC BY 4.0) license, which permits unrestricted use, distribution, and reproduction in any medium, provided the original work is properly cited. To view a copy of this license, visit https://creativecommons.org/licenses/by/4.0/. This license does not apply to figures/photos/artwork or other content included in the article that is credited to a third party; obtain authorization from the rights holder before using such material.

\section{SUPPLEMENTARY MATERIALS}

science.sciencemag.org/cgi/content/full/science.abd7728/DC1

Materials and Methods

Table S1

References

MDAR Reproducibility Checklist

10 July 2020; accepted 26 October 2020

Published online 28 October 2020

10.1126/science.abd7728 
A

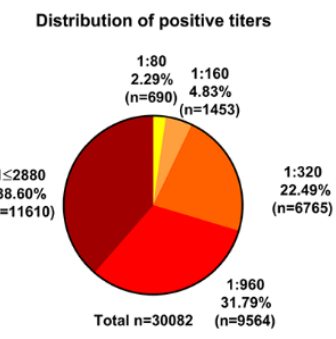

B

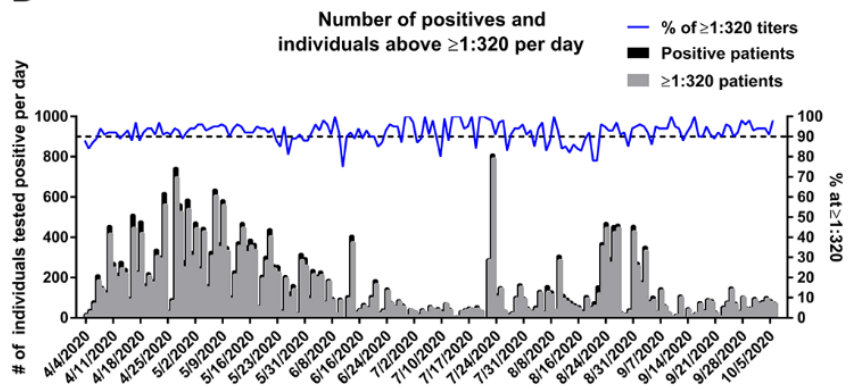

Fig. 1. SARS-CoV-2 spike antibody titers in 30,082 individuals. (A) The percentage of individuals with antibody titers of 1:80 (low), 1:160 (low), 1:320 (moderate), 1:960 (high), and $\geq 1: 2880$ (high). (B) Absolute numbers and percent of individuals with titers of 1:320 over time. Testing of each sample was performed once in a Clinical Laboratory Improvement Amendments (CLIA)-certified laboratory using an assay that received emergency use authorization (EUA) from the FDA.

A

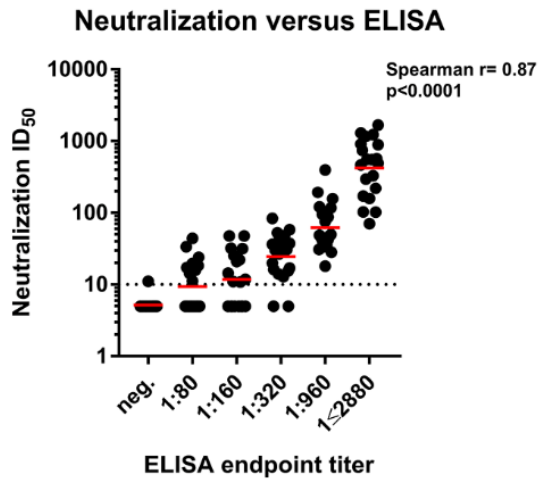

B $\%$ of samples with neutralizing activity (cutoff $\mathrm{ID}_{50}$ of $>1: 10$ )

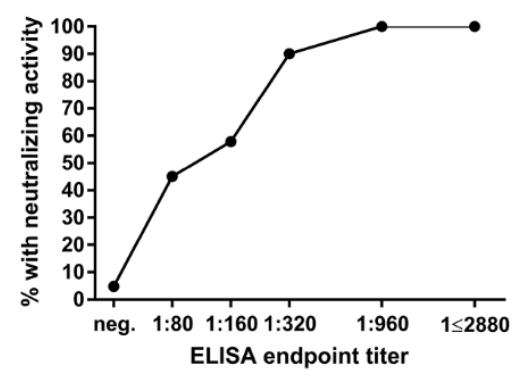

Fig. 2. Neutralizing activity of serum samples in relation to ELISA titers. (A) A correlation analysis between ELISA titers on the $x$ axis and neutralization titers in a microneutralization assay on the $y$ axis. The Spearman $\rho$ was determined. Red bars indicate the geometric mean. (B) The proportion of sera that exert any neutralizing activity in each of the ELISA titer categories. Testing was performed once using an FDA EUA ELISA in a CLIA laboratory or twice following a standardized neutralization protocol. 

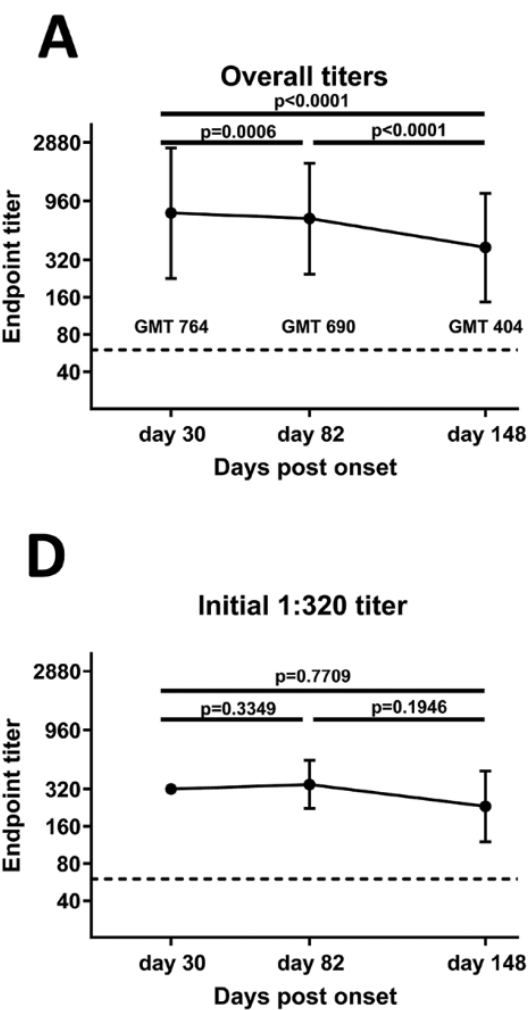

G

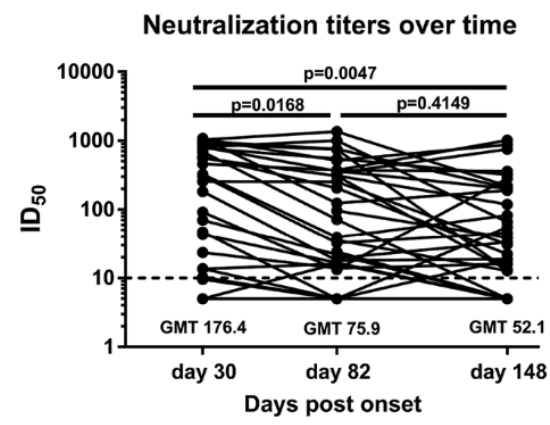

B

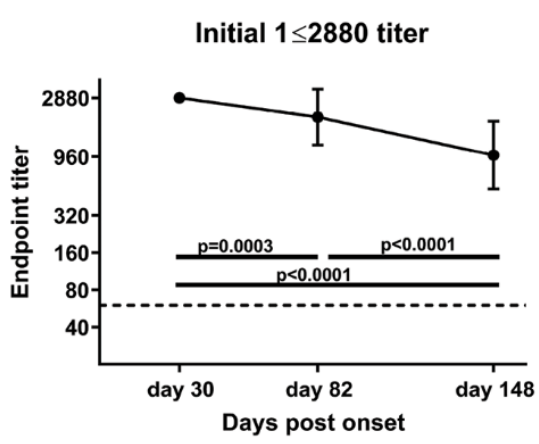

$\mathbf{E}$

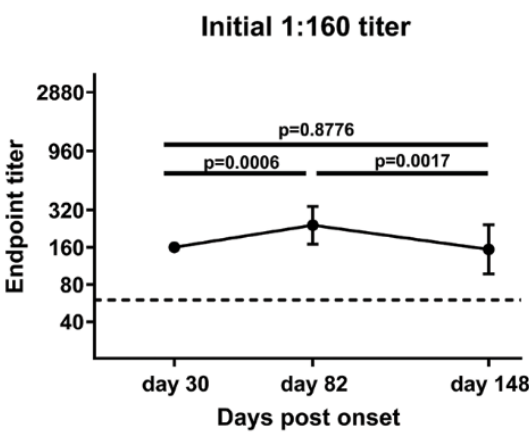

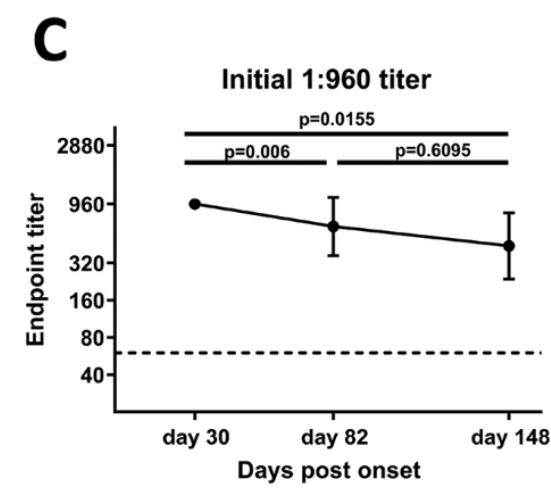

$\mathbf{F}$

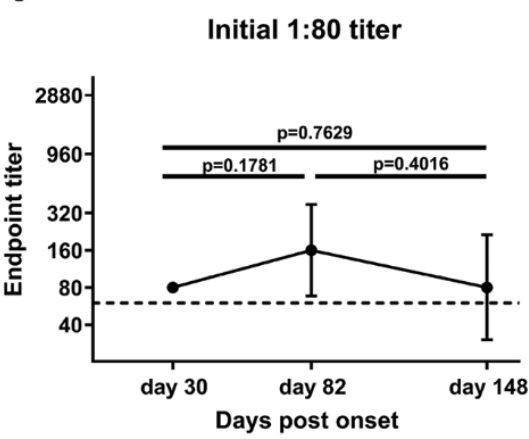

\section{H Correlation of neutralization versus}

ELISA at day 148 time point

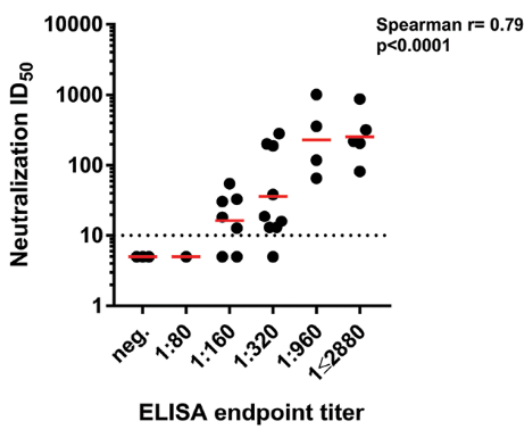

Fig. 3. Antibody titer stability over time. (A) Titers of 121 volunteers who were initially bled approximately 30 days post COVID-19 symptom onset and were then recalled and bled again approximately 82 days and 148 days post symptom onset. (B to F) The same data but stratified by the initial/day 30 titer. Titers are graphed as geometric mean titers (GMT) with geometric standard error. (G) Neutralization titers of 36 subjects over time. A paired one-way ANOVA corrected for multiple comparison was used to determine statistical significance. $(\mathrm{H})$ A correlation analysis between ELISA titers on the $x$ axis and neutralization titers in a microneutralization assay on the $y$ axis at day 148. Red bars indicate the geometric mean. The Spearman $\rho$ was determined. Testing was performed once using an FDA EUA ELISA in a CLIA-certified laboratory or twice following a standardized neutralization protocol. 